\title{
Positioning of selected Middle Eastern airlines in the South African business and leisure travel environment
}

\author{
Svetlana Surovitskikh ${ }^{a}$ and Berendien Lubbe ${ }^{b}$ \\ ${ }^{a}$ TuksSport (Pty) Ltd., University of Pretoria, South Africa \\ ${ }^{\mathrm{b}}$ Department Tourism Management, University of Pretoria, South Africa
}

\begin{abstract}
The study examines the positioning of four selected Middle Eastern airlines in the South African business and leisure travel environment. The positioning of the airline indicates how passengers rate the airline based on their expectations of that particular airline in terms of service quality attributes deemed important by passengers. Airline service quality attributes were grouped using factor analysis and positioning maps were generated based on statistically significant attributes of service, using a 3D centroid plot. The results suggest that passengers have different expectations of different airlines and that an airline's performance can be measured against these expectations, rather than against a standard set of service attributes.
\end{abstract}

Keywords: Airline positioning; Service quality; Business travel; Leisure travel; South Africa

\section{Introduction}

Perceptual or positioning mapping is a tool that helps marketers to understand customers' perceptions of different products or brands in the market. Service quality is an integral part of the positioning strategy, since services in the airline 
industry are dependent on customers' perceptions and expectations of the airline product. Studies in the airline industry have focused on the demand for airlines with service quality as central to the choice of airlines for both business and leisure travellers (Aksoy et al., 2003; Chang and Yeh, 2002; Sultan and Simpson, 2000; Tsaur et al., 2002). Studies on the positioning of airlines based on service quality attributes are less frequent (Gursoy et al., 2005). The focus here is on the customers' perceptions and expectations of airline performance based on service quality attributes, and the results are used to map the position of four selected airlines. Airlines adopt positioning strategies to ensure that they are differentiated and positively perceived by their potential and current passengers. The question is whether passenger perceptions of an airline's position in terms of its service quality match the expectations created by that airline. This study aims to answer this question by identifying service quality attributes that are important to passengers of specific airlines and determining how those airlines are positioned in terms of their passengers' expectations.

Among a wide range of role players within the air transportation market, a few airlines, through their service quality strategies rather than low-cost strategies, have succeeded in penetrating developing markets, one of which is South Africa, and in so doing affected the well-established European airlines' market share in these markets. After a period of sanctions and with the democratization of the country, international commercial airline activity settled down and in the 1990s all overseas airlines operating in South Africa confronted deregulation, privatization, mergers and alliances, technological shifts and route reconfiguration (Goldstein, 2001). This opened the door to a flurry of new airlines entering the market, among them airlines from the Middle East. The recent entry and growth of the Middle Eastern airlines such as Etihad, Emirates, Gulf Air and Qatar Airways created strong competition for well-established carriers. These airlines adopted distinct positioning strategies for entry into the market.

Based on information communicated by the selected airlines in the media and through their websites, the airlines appear to be implementing the following 
positioning strategies on the selected route between South Africa and the Middle East. Reliability and product augmentation are the two main positioning strategies followed by Etihad. The main focus of Emirates falls on innovativeness and customization of its product. Gulf Air follows two main strategies: a superior product offering through technology and customization. Qatar Airways' main focus is on personal service ("people advantage") and augmentation of the product offering. Although these airlines have affected the market share of established airlines, they are, at the same time, competing with one another in a relatively small market. The problem is whether management can assess correctly what passengers expect. Expectations serve as reference points for customers. In evaluating the airline's positioning based on service quality aspects, passengers compare what they perceive they are given in a service encounter with their expectations of that encounter (Gilbert and Wong, 2003). In this respect, the positioning strategy of the airline is crucial.

\section{Service quality and positioning}

The quality of airline service is difficult to define and measure due to its heterogeneity, intangibility and inseparability. The results of existing studies into service quality suggest that definitions and perceptions of airline service quality are quite diverse and do not seem to fit any single existing quality model (Haynes and Percy, 1994). Several conceptual and empirical studies have been devoted to investigating the service quality issues in the airline industry. The SERVQUAL Model used by Gordon (1991) and Tsaur et al. (2002) to measure service quality in the airline industry identified 15 service quality attributes and grouped these into five categories. Tsaur et al. also found that different individuals usually exhibit a wide range of perceptions regarding the quality of service. The Kano model identifies similar service quality attributes but proposes that services fall into three categories based on how they are perceived by the customer and by their effect on customer satisfaction (Jordaan and Prinsloo, 2001). Table 1 shows the attributes and categories identified by each model. 
Table 1

Service quality attributes for airlines

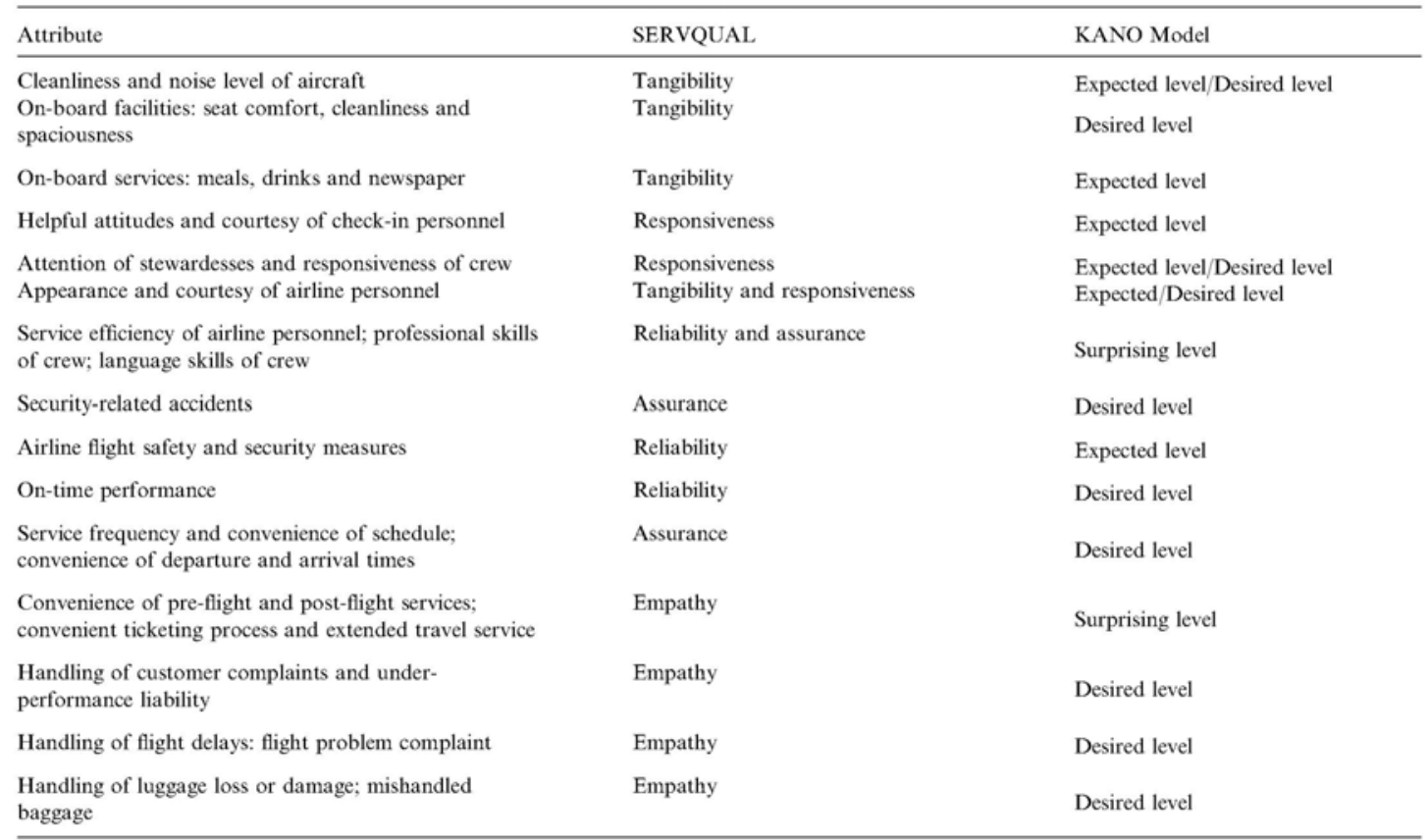

A number of authors agree that service quality plays an integral role in the positioning of organizations, particularly in the service industries (Blankson and Kalafatis, 2001; Jordaan and Prinsloo, 2001). Empirical evidence has indicated that success in customer-focused service development requires a deep understanding of customer needs, expectations and preferences (Gustafsson et al., 1999) and that marketing strategies implemented by airlines to expand internationally must take into consideration different expectations and perceptions of passengers (Sultan and Simpson, 2000). According to Dibb et al. (1997), "positioning is based on consumers' perceptions and is therefore only partly in the control of marketers...in-depth market research is required if customer motivations and expectations in a particular market are to be fully 
understood...management's intuition is not always sufficient...". Positioning is also about how the product compares, in the customer's mind with competing offerings. The position that a product occupies is shaped by existing brands in the market. It is widely accepted that customers first assign a position to the bestknown or market-leading brand. This position is usually the standard against which other brands are compared (Dibb et al., 2000). Brooksbank (1994) suggests that the choice of differential advantage as reflected in the positioning strategy defines how an organization will compete with rivals in the segment. This was also shown in the study by Gursoy et al. (2005), who used 15 attributes that measure actual airline performance in terms of critical quality criteria important to customers and used their results to position airlines according to their service quality profiles. Brooksbank also suggests that the choice of the target market segment, which describes the customers an organization will seek to serve, is part of the positioning strategy. In the airline industry, two main segments are generally recognized, business and leisure and any study done to assess positioning strategies needs to differentiate between the perceptions of these two groups.

\section{Methodology}

The main objective of the study was to examine the positioning of four selected Middle Eastern airlines in the South African business and leisure travel environment based on travellers' perceptions of service quality attributes. The research design relied mainly on using a revealed-preference approach to assess the expectations and perceptions of business and leisure travellers of the service attributes of the four Middle Eastern airlines. The process followed was to establish criteria for evaluating service quality as determined through the literature and those revealed through the communication media of the four airlines. Thirty-five variables, which represent passengers' perceptions and expectations of service quality that may differ in importance to travellers, were derived. The population used was defined as business and leisure passengers who had used the services of one or more of the four Middle Eastern airlines. 
Since it was not possible to obtain databases from each of the four airlines, random sampling could not be done, and it was decided to collect data from a number of sources to ensure that all four airlines would be represented in the sample as well as equal numbers of business and leisure travellers.

The respondents' selection was based on the representation of the market share of the selected airlines. According to a reliable source from the airline industry, the market share of each of the four airlines in 2006 was as follows: Emirates $-55 \%$, Qatar Airways $-20 \%$, Gulf Air $-13 \%$ and Etihad Airways with $12 \%$ of the market share. The objective was to select the respondents in this approximate ratio to ensure that each airline is represented according to its share in the market.

Departing passengers at the OR Tambo airport were approached over a number of different days over a period of 2 months. Certain travel agencies who specialize in travel to the Middle East were approached and questionnaires handed out to their passengers. A structured self-administered questionnaire was used to elicit responses. In total, 410 useable questionnaires were collected. No incentives were provided to respondents for completing the questionnaire.

\section{Data analysis and results}

Data analysis process initially generated descriptive statistics to profile the respondents in terms of demographic characteristics, travel behaviour and the importance of the identified service attributes. ${ }^{1}$ The demographic profile of the respondents showed $67 \%$ male and $33 \%$ female, in two main age groups: $41 \%$ below 30 years and with $40 \%$ between 30 and 45 years.

\footnotetext{
${ }^{1}$ Data processing was performed using $\mathrm{SAS}^{\circledR}$ version 8.2 under VM/CMS on the mainframe computer of the University of Pretoria.
} 
Half of the respondents were from South Africa, while 29\% were from the Middle East. As far as home language is concerned $29 \%$ of respondents speak Arabic, $26 \%$ English, 16\% Afrikaans and $14 \%$ an African language. The remaining $25 \%$ spoke other languages. Eighty-three percent fell into a medium income bracket. The purpose of travel indicated that $38 \%$ of respondents travelled for business, $34 \%$ for leisure and $28 \%$ for other reasons, including commuting, visiting friends and relatives and attending sports events. For half of the respondents $(50 \%)$, the airline of choice for business travel is Emirates, followed by Qatar (24\%), Etihad $(14 \%)$ and Gulf Air (12\%). The airline of choice for leisure travel indicated that 49\% choose Emirates, 22\% Qatar, 18\% Etihad and 11\% Gulf Air. In considering the reasons for their choice of airline for both business and travel, service quality was chosen as the reason by the majority of $(62 \%)$ of respondents with convenience of flight times and airport facilities also selected by $41 \%$ and $38 \%$, respectively. Respondents could select more than one, so the total exceeded $100 \%$.

Respondents were asked to rate each of the 35 service quality attributes on a scale with values from 1 to 7 with 1 meaning not at all important and 7 extremely important. The arithmetic averages and standard deviation were calculated. Respondents did not rank any service attribute as unimportant, all service attributes being ranked from 5,6 or 7 ( 5 would also mean that the service attribute was important but could probably not be regarded as the most important). Within this range the most important service attribute was associated with a "good system of handling luggage loss or damage" (the mean value was 6.42), followed by "the airline has efficient check-in and baggage handling facilities". The least important service attributes are "the airline provides in-flight internet/email/fax/phone facilities" followed by "the airline has other travel-related partners, for example cars, hotels and travel insurance".

To group the 35 service attributes into manageable categories for generating statistically significant positioning maps, three further techniques were applied: factor analysis; two-way analysis of variance (ANOVA) to test the relationship 
between variables and the factors; and multivariate analysis of variance (MANOVA) to simultaneously test all variables and their interrelationships in order to avoid any erroneous conclusions. The study made use of the principal factor analysis with the objective of grouping the 35 variables into a minimum number of factors for prediction purposes. In this study, three criteria were employed to determine the number of factors to be extracted: the eigenvalues, a priori criterion and a screen test. All 35 variables evidenced factor loadings greater than 0.30 and three factors were generated, which could provide for adequate interpretation of the variables under examination. The three factors were named as follows: Factor 1-consistency of service (variables include ontime performance, good ground services, quality food and beverages, ability of airline to perform right the first time from booking to arrival, understanding customer specific needs, courtesy of employees, crew communication in desired language); Factor 2-reliability (variables include efficient check-in and baggage handling, handling luggage loss or damage, safety and security, handling of flight delays, sufficient legroom, employee willingness and prompt service). Factor 3augmented products (variables include a sound loyalty programme, air and accommodation packages, in-flight internet/fax phone facilities, global alliance partners, comfortable lounges, in-flight entertainment). The Cronbach alpha coefficient was employed to measure the reliability of variables within factors. ${ }^{2}$

To test the relationship between the independent variables: gender, age, nationality, home language, income group, purpose of travel and carrier, and dependent variables: factors 1,2 and 3 , an ANOVA was done. To comply

\footnotetext{
${ }^{2}$ To cross-validate the results obtained, the internal consistency reliability for each factor was computed and yielded high Cronbach alpha coefficients ranging between 0.78 and 0.87 . The coefficient for factor 1 equals 0.84 , indicating a good match among variables within the factor; for factor $2,0.87$, indicating a very good match among variables within the factor, while for factor 3 it equaled 0.79 , which was deemed acceptable. The correlations between factors are: 0.35 between factors 1 and $2 ; 0.26$ between factors 1 and $3 ; 0.31$ between factors 2 and 3 .
} 
with the assumptions for ANOVA that the residuals must be normally distributed and the variances must be equal, the data were transformed using a ranking method with a BLOM option. The covariate that was used in this model is the total number of times, which passengers flew on each of the respective Middle Eastern carriers in both 2005 and $2006 .^{3}$ The question representing importance of attributes of service quality did not contain any indication, of which carrier was specified when the respondent rated service attributes. To eliminate this problem, where more than one carrier was used, the carrier with which passengers had flown the most was selected. Where different carriers were used an equal number of times, a random pick was made.

ANOVA was used to test the relationship between the variables and the three factors in the general linear model. ANOVA analyses were applied for each ranked factor mean residue. The independent variables were: age, gender, nationality, home language, income group, purpose of travel and times flown as the covariate variable. Using the two-way ANOVA significant results at a $p$ value of less than $5 \%$, Table 2 shows that a relationship exists between certain independent variables and the importance that is attached to certain factors. The post hoc pairwise comparisons were done using least-square means-predicted populations margins estimate the marginal means over a balanced population.

\footnotetext{
${ }^{3}$ The covariate was employed to correct the number of times a specific carrier was used.
} 
Table 2

Summary table for two-way ANOVA

\begin{tabular}{lclll}
\hline Source & $\begin{array}{c}\text { Degree of } \\
\text { freedom }\end{array}$ & $\begin{array}{l}\text { Mean } \\
\text { square }\end{array}$ & $F$ Value & $p$ Value \\
\hline $\begin{array}{l}\text { Factor 1 consistency } \\
\text { of service }\end{array}$ & & & \\
Age & 2 & 3.76 & 4.49 & 0.01 \\
Number of flights & 1 & 4.48 & 5.36 & 0.02 \\
Factor 2 reliability & 2 & 6.97 & 8.77 & 0.00 \\
Age & 2 & 2.94 & 3.70 & 0.06 \\
Income group & 4 & 2.54 & 3.20 & 0.01 \\
Purpose of travel & 3 & 2.41 & 3.03 & 0.03 \\
Carrier & 2 & & & \\
Factor 3 augmented products & 2.68 & 2.91 & 0.06 \\
Nationality & & & & \\
\hline
\end{tabular}

The results show that in the South African environment significant relationships exist between certain variables and factors as identified. Age and the number of flights undertaken are determinants of the importance attached to factor 1consistency of service. Respondents in the age group between 30 and 45 years (mean of 6.02) attached the most importance to consistency of services, followed by respondents over 45 years (6.00) and respondents below 30 years of age (5.87). The least-square means for factor 1 and age indicates that there is significant difference between the means of age group one (below 30 years) and age group two (30-45 years).

There was also a significant relationship between factor 2-reliability of services and age, income group, purpose of travel and carrier. Respondents in the age group between 30 and 45 years $(M=6.30)$ attached the most importance to reliability of services, followed by respondents over 45 years $(M=6.20)$ and respondents below 30 years of age $(M=6.08)$. The least-square means for factor 
2 and age indicates that there is significant difference between the means of age group one (below 30 years) and age group two (30-45 years), the means of age group one and age group three (over 45 years).

Respondents in the income group below $R 250,000$ attached the most importance to reliability of services, followed by respondents in the income group between $R 250,000$ and $R 500,000$ and respondents above $R 500,000$ per annum. The least-square means for factor 2 and income group indicates that significant difference exists between the means of income group one (below $R$ 250,000 per annum) and group two (between $R 250,000$ and $R$ 500,000 per annum), the means of income group one and income group three (over $R$ 500,000 per annum).

Respondents travelling on Gulf Air (mean of 6.33) attached the most importance to the reliability of services, followed by respondents travelling Emirates, Etihad and Qatar Airways. The least-square means for factor 2 and the carrier used indicate that there is significant difference between the means of Qatar Airways and Emirates, Qatar Airways and Gulf Air, Qatar Airways and Etihad.

The results showed a significant relationship between factor 3-augmented products and nationality of respondents. Respondents from Middle East attached the most importance to factor 3-augmented products (mean of 5.92), followed by respondents from other countries (European and African countries) with (5.73) and respondents from South Africa (5.60).

The least-square means for factor 3 and nationality indicates that there is significant difference between the means of respondents from Middle East and South Africa, respondents from Middle East and other countries.

MANOVA was used to assess multivariate differences across the groups to determine if there is an overall effect of variables on the three factors. Using the Wilks' Lambda test Table 3 shows the statistically significant results obtained (at a $p$-value of less than $5 \%$ ): 
Table 3

MANOVA test of significance for an overall effect of variables on all three factors

\begin{tabular}{llll}
\hline Variable & Value & $F$ Value & Significance of $F$ \\
\hline Age & 0.95 & 3.43 & 0.00 \\
Language & 0.93 & 2.29 & 0.01 \\
Income & 0.95 & 3.30 & 0.00 \\
Purpose of travel & 0.94 & 1.84 & 0.04 \\
Carrier & 0.95 & 2.15 & 0.02 \\
\hline
\end{tabular}

The MANOVA test confirmed that a relationship exists between age, language, income, purpose of travel and carrier used, and all three factors but does not explain the individual relationship. Finally, positioning maps were generated from the statistically significant results by using 3D centroid plots to depict the position of each of the four airlines along the three factors as perceived by those passengers who had flown the most on the selected airline. Fig. 1 depicts the positioning of Qatar Airways, Emirates, Gulf Air and Etihad for business and leisure travel relative to the perceived level of importance of the three factors, representing all the attributes of service quality. Each of the axes of 3D Centroid plot is represented by the specific factor. Axis $Z$ represents factor 1: "consistency of service", axis $X$ represents factor 2: "reliability of services" and axis $Y$ represents factor 3: "augmented products". The positioning of each airline, relative to the importance of the three factors, was plotted using the mean values of each factor relative to the airline (Fig. 2). 


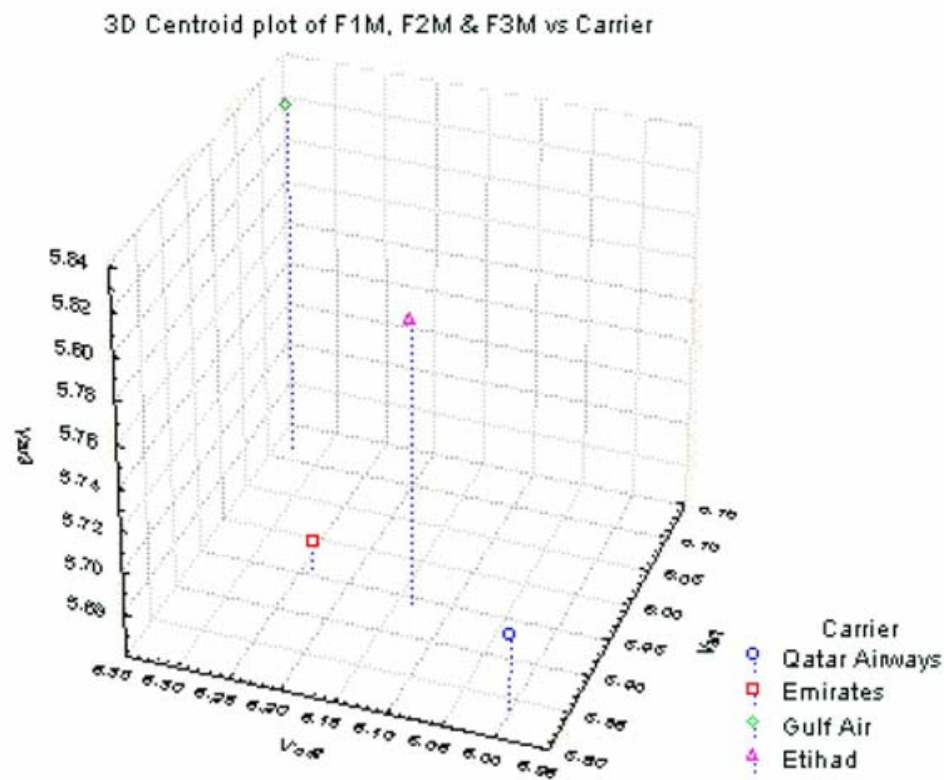

Fig. 1. Positioning of Qatar, Emirates, Gulf Air and Etihad based on identified factors (business and leisure travel).

3D Centroid plot of transtormed v91, v90 \& V65 vs Business carrier

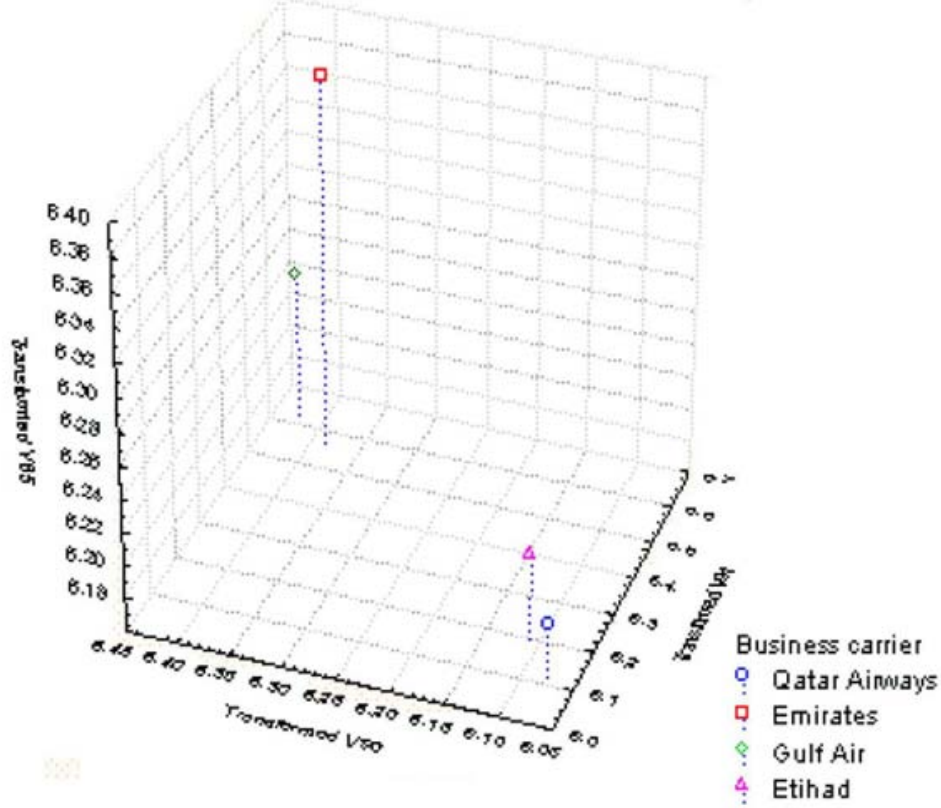

Fig. 2. Positioning of Qatar, Emirates, Gulf Air and Etihad in terms of three service attributes for business travel. 
The results show that business and leisure passengers rate Gulf Air the highest in terms of the level of importance attached to all three factors in the light of their expectations and perceptions of the service rendered. In other words, passengers who have flown Gulf Air the most, attach the highest level of importance to "reliability of services" $(M=6.33)$, followed by passengers of Emirates, who attach a slightly lower level of importance to this factor. Etihad passengers attach a lower level of importance to "reliability of service", while Qatar passengers attach the least high level of importance to this factor. In terms of expectations, Emirates is rated second on factors 1 and 2, and Etihad Airways is rated second on factor 3. Qatar Airways is rated lowest on factors 1 and 2, and Emirates lowest on factor 3.

A 3D positioning map was also generated for the positioning of each of the four airlines for business travel relative to the level of importance attached to three attributes of service quality in the light of their expectations and perceptions and the service rendered. The positioning is for business travel only, since the positioning of airlines for leisure travel where these attributes were concerned was not statistically significant. Each of the axes of the 3D centroid plot is represented by the specific variable. Axis $Z$ represents variable V91: "the airline has a good system of handling luggage loss or damage", axis $X$ represents variable V90: "the airline has a good system of handling flight delays", while axis $Y$ represents variable V65: "the airline makes you feel safe".

In terms of the three identified service attributes and passenger expectations and perceptions of service rendered, Gulf Air was again rated highest on variables relating to their system of handling of luggage loss and flight delays. Emirates rated highest on perception of safety and second on luggage loss and flight delays handling. Etihad was rated third on all service attributes and Qatar fourth. 
From the results, the alternative hypothesis cannot be rejected. It can thus be said that the relative positioning of the selected airlines differs based on business and leisure travellers' expectations and perceptions of service quality attributes.

\section{Discussion}

The airlines were divided into the four carriers and perceptions and expectations of service attributes were categorized into three factors: "consistency of service", "reliability of service" and "augmented products". There was a significant difference in the positioning of the four carriers based on passengers' expectations of a particular airline and their rating of important service attributes offered by that airline. With prior studies the focus has been on identifying important service attributes in the airline environment and positioning airlines based on those identified service attributes. Here a further dimension is added. Through their positioning strategies as presented in their communication media airlines create certain expectations of their service quality. Passengers rate an airline's performance based on these expectations and those service quality attributes deemed important by passengers. Thus, where previous studies have measured the performance of airlines against the same set of service quality attributes, this study has succeeded in measuring service attributes deemed important by passengers for a particular airline based on their expectations of that airline. Three service attributes were also identified that proved important to passengers. Two of these related to baggage handling. This result must be seen in the context of the serious baggage problems experienced at the OR Tambo International Airport in Johannesburg, which has created a great deal of negative publicity. The positioning of the airlines along these attributes was also done and significant differences in passenger expectations and ratings against these expectations were found.

Some circumspect comparisons of the results against the portrayed positioning strategy of the airlines can be attempted. Gulf Air's main positioning strategies appear to rest on providing a superior product through technology and 
customization of services. From the results, it appears that Gulf Air has achieved the highest score of all four airlines in meeting passengers' expectations of what the airline offers. Emirates' main positioning strategy appears to rest on innovativeness and customization. Emirates passengers give the airline a high score, but it does not appear to succeed as well as Gulf Air in meeting passenger expectations. Etihad's main positioning strategies appear to revolve around reliability and the augmentation of the service offering. Its passengers expect reliability and although it also rates highly, it has achieved a lower score than both Gulf Air and Emirates. Qatar Airways' main positioning focuses on its personal ("people advantage") and augmented products. In terms of passenger expectations of what Qatar Airways offers, this airline achieved the lowest rating by its passengers.

\section{Conclusion}

The study examined the positioning of four selected Middle Eastern airlines in the South African business and leisure travel environment. The positioning of the airlines indicated how passenger' rate the airlines, based on their expectations of the particular airline in terms of service quality attributes deemed important by passengers. The results suggest that passengers have different expectations of different airlines and that an airline's performance can be measured against these expectations, rather than against a standard set of service attributes. This study had certain limitations in terms of the normality of the data and the scale used for rating the importance of service attributes, which had to be overcome using specific analysis techniques. The results generated proved valuable and the study succeeded in extending the scope of how an airline's performance can be rated. Passengers have different expectations of what different airlines can offer in terms of service quality. This is the foundation of how airlines differentiate themselves through their positioning strategies. Passengers rate the airline's performance against their expectations of that particular airline and not necessarily against a standard set of service attributes against which all airlines should be rated. 


\section{Acknowledgements}

We would like to thank Mike van der Linde and M Graham of the Department of Statistics at the University of Pretoria for assistance with this research.

\section{References}

Aksoy et al., 2003 S. Aksoy, E. Atilgan and S. Akinci, Airline services marketing by domestic and foreign firms: differences from the customers' viewpoint, Journal of Air Transportation Management 9 (2003), pp. 343-351.

Blankson and Kalafatis, 2001 C. Blankson and S. Kalafatis, The development of a consumer/customer-derived generic typology of positioning strategies, Journal of Marketing Theory and Practice 9 (2001), pp. 35-54.

Brooksbank, 1994 R. Brooksbank, The anatomy of marketing positioning strategy, Marketing Intelligence and Planning 12 (1994), pp. 10-15. Chang and Yeh, 2002 Y.H. Chang and C.H. Yeh, A survey analysis of service quality for domestic airlines, European Journal of Operational Research 139 (2002), pp. 166-177.

Dibb et al., 1997 S. Dibb, L. Simkin, W. Pride and O.C. Ferrell, Marketing (third ed), Houghton Mifflin, Boston (1997).

Dibb et al., 2000 S. Dibb, L. Simkin, W. Pride and O.C. Ferrell, Marketing: Concepts and Strategies (fourth ed), Houghton-Mifflin, Boston (2000). Gilbert and Wong, 2003 D. Gilbert and R.K.C. Wong, Passenger expectations and airline services: a Hong Kong based study, Tourism Management 24 (2003), pp. 519-532.

Goldstein, 2001 A. Goldstein, Infrastructure and development and regulatory reform in Sub-Saharan Africa: the case of air transport, World Economy 24 (2001), pp. 221-248.

Gordon, 1991 E.W. Gordon, Evaluation criteria considered by consumers when selecting an air carrier-a factor analysis, University of Pretoria, Pretoria (1991) (Unpublished DSc Thesis). 
Gursoy et al., 2005 D. Gursoy, M.H. Chen and H.J. Kim, The US airlines relative positioning based on attributes of service quality, Journal of Tourism Management 26 (2005), pp. 57-67.

Gustafsson et al., 1999 A. Gustafsson, F. Ekdahl and B. Edvardsson, Customer focused service development in practice-a case study at Scandinavian Airlines System (SAS), International Journal of Services Industry Management 10 (1999), pp. 344-358.

Haynes and Percy, 1994 R. Haynes and J. Percy, Perception paradox: airline service quality issues, Proceedings of Decision Sciences Institute 1994 Annual Meeting 3 (1994), pp. 1950-1952.

Jordaan and Prinsloo, 2001 Y. Jordaan and M. Prinsloo, Grasping Service Marketing (second ed), Grapevine News, S.I (2001).

Sultan and Simpson, 2000 J.F. Sultan and M.C. Simpson, International service variants: airline passenger expectations and perceptions of service quality, Journal of Services Marketing 14 (2000), pp. 188-216.

Tsaur et al., 2002 S.H. Tsaur, T.Y. Chang and C.H. Yen, The evaluation of airline service quality by fuzzy MCDM, Tourism Management 23 (2002), pp. 107-115. 